\title{
Re: Abdelrahman A, Moore A, Trochez R. Use of surgical databases in urogynaecology
}

\author{
Hjalmar A. Schiøtz ${ }^{1}$ (D) $\cdot$ Rune Svenningsen ${ }^{2,3} \cdot$ Sigurd Kulseng-Hanssen $^{3} \cdot$ Tomislav Dimoski $^{3}$
}

Received: 23 June 2019 / Accepted: 16 July 2019 / Published online: 26 July 2019

(C) The International Urogynecological Association 2019

We have read with great interest the editorial 'Use of surgical databases in urogynaecology' by Abdelrahman, Moore and Trochez [1], and we agree wholeheartedly that good quality surgical registries are needed and that compulsory registries ensure better data quality.

However, we were somewhat surprised to see that one of the oldest registries, The Norwegian Female incontinence registry (https://www.kvalitetsregistre.no/registers/norskkvinnelig-inkontinensregister), was not mentioned in the editorial. The Norwegian Female incontinence registry is a nationwide, compulsory quality registry for incontinence surgery performed in Norway. It was founded in 1998 and thus celebrated its 20th anniversary last year. The coverage rate is currently $98.5 \%$ and the registry was recently awarded stage IV status, the highest possible quality rating in Norway. More than 2500 new procedures are recorded each year and the registry now contains data on nearly 35,000 procedures.

Subjective and objective data from the pre- and postoperative (6 months and 3 years) evaluations as well as the procedure and any per- or postoperative complications are recorded consecutively in a local database within each hospital. Written consent is obtained from the patients. Anonymized data are transferred to the national registry. Data quality is validated at several levels including comparison with each hospital's electronic patient records.

Hjalmar A. Schiøtz

s-schi@online.no

1 Department of Obstetrics and Gynecology, Vestfold Hospital Trust, Tønsberg, Norway

2 Department of Gynecology, Oslo University Hospital, Ullevål, Oslo, Norway

3 The Norwegian Female Incontinence Registry, Oslo University Hospital, Ullevål, Oslo, Norway
Each department can use its local registry for quality assurance purposes. The registry issues annual reports of national and department level results to all participating departments and also reports detailed results to each individual department at surgeon level. The main results with the exception of the data on individual surgeons are made publicly available online (https://www.kvalitetsregistre.no/registers/norsk-kvinneliginkontinensregister).

So far, 13 articles (plus 2 recently submitted to the IUJ) based on data from the registry have been published in international peer-reviewed journals.

\section{Compliance with ethical standards}

Conflicts of interest None.

\section{References}

1. Abdelrahman A, Moore A, Trochez R. Use of surgical databases in urogynaecology. Int Urogynecol J. 2019;30:851-2. https://doi.org/ 10.1007/s00192-019-03943-8.

Publisher's note Springer Nature remains neutral with regard to jurisdictional claims in published maps and institutional affiliations. 